Didáctica. Lengua y literatura

ISSN: 1130-0531

http://dx.doi.org/10.5209/DIDA.61956

\title{
Escritura creativa e igualdad: versiones de los cuentos tradicionales
}

\author{
Pilar García Carcedo ${ }^{1}$
}

Recibido: 10 de marzo de 2018 / Aceptado: 2 de agosto de 2018

Resumen. El cuento como recurso educativo puede ser una herramienta muy útil. En estas páginas se busca una revitalización del juego con los cuentos tradicionales en las aulas a través de la escritura creativa y se reflexiona sobre las polémicas feministas en torno a dicha tradición, con el objetivo de favorecer una educación en igualdad sin prescindir de los cuentos. Se presenta una propuesta didáctica que empieza con la revisión de las versiones más antiguas de dos de los cuentos tradicionales más conocidos: Cenicienta y La Bella Durmiente. Los resultados de la investigación incluyen estrategias didácticas que implican a los estudiantes de una forma activa en el proceso de aprendizaje a través de la escritura creativa 2.0 a partir de cuentos tradicionales.

Palabras clave: Cuentos tradicionales; didáctica; escritura creativa; educación en igualdad; recurso educativo.

\section{[en] Creative Writing and Equality: Versions of Traditional Tales}

\begin{abstract}
The story as an educational resource can be a very useful tool. This article proposes creative writing with traditional tales and it offers a reflection about polemic feminist approaches to this tradition, with the goal to promote equality education with popular tales. It presents a didactic proposal that begins with the research of ancient versions of two of the best-known fairy tales: Cinderella and Sleeping Beauty. The results from this research include teaching strategies that actively engage students in the learning process through 2.0 creative writing from traditional tales.
\end{abstract}

Keywords: Fairy tales; didactics; creative writing; equality learning; educational resource.

\section{[fr] Écriture créative et égalité: versions des histoires traditionnelles}

Résumé. L'histoire traditionnelle en tant que ressource éducative peut être très utile. Ces pages cherchent à revitaliser le jeu avec des histoires traditionnelles et d'écrits créatifs en classe et à réfléchir aux controverses féministes entourant cette tradition, dans le but de promouvoir une éducation à l'égalité sans renoncer aux comptes. Une proposition didactique est présentée qui commence par la révision des versions les plus anciennes de deux des histoires traditionnelles les plus connues: Cendrillon et $\mathrm{La}$ Belle au bois dormant. Les résultats de la recherche incluent des stratégies didactiques qui impliquent les élèves de manière active dans le processus d'apprentissage par le biais de l'écriture créative 2.0 à partir d'histoires traditionnelles.

Mots-clé: Histoires traditionnelles; didactique ; écriture créative; l'éducation dans l'égalité; ressource éducative.

1 Universidad Complutense de Madrid (España)

E-mail: pcarcedo@edu.ucm.es 
Sumario. 1. Introducción. Interés didáctico de los cuentos tradicionales. 2. Educación en igualdad. Feminismo y polémicas sobre los cuentos. 3. Experiencia de escritura creativa y digital en las aulas. 4 . Las primeras Cenicientas. 4.1. Propuesta didáctica: Microrrelatos. 5. La Bella durmiente se enfrenta al ogro. 5.1. Propuesta didáctica: La princesa decide en video. 6. Conclusiones. 7. Referencias bibliográficas.

Cómo citar: García Carcedo, P. (2018) Escritura creativa e igualdad: versiones de los cuentos tradicionales, Didáctica. Lengua y literatura, 30, 87-103.

\section{Introducción. Interés didáctico de los cuentos tradicionales}

En el instante de depositar su beso sobre la Bella Durmiente, el príncipe se da cuenta de que él amaba a otra doncella que duerme lejos, en otro bosque y otro cuento, Blancanieves (Navascués 2012, 66).

La reescritura de cuentos tradicionales es una estrategia fácil y altamente motivadora para las aulas, puesto que remiten a intertextos muy conocidos por todos desde la más tierna infancia. En el inicio estos cuentos no eran para niños, estaban destinados a un público adulto y eran tan antiguos como el mundo, por lo que suponen un bagaje cultural irrenunciable que se debe recuperar en las aulas del siglo XXI. Han sufrido muchas modificaciones a lo largo de los siglos, como se verá en estas páginas, y han sido trasladados al papel por recopiladores como Perrault y los hermanos Grimm, que los han ido adaptando a la infancia. Porque la literatura específicamente destinada al público infantil no surge hasta el siglo XVIII, coincidiendo con la extensión de la escolarización (Colomer, 2010). La expansión social de los relatos tradicionales en la actualidad se extiende más allá de los libros, llegando al cine, al cómic e incluso a la publicidad, como se puede comprobar en los estudios de Zapico Lamela (2015), Levorato (2003) o en The Routledge Companion to Media and Fairy-Tale Cultures (Greenhill et al., eds., 2018).

La corriente psicoanalítica, con Bruno Bettelheim (1999), destacó la importancia de los cuentos para el desarrollo de la personalidad de los niños y jóvenes. Así como la utilidad de los cuentos para la expansión de su competencia literaria: aprendizaje de las posibilidades de estructurar una narración, o de las expectativas sobre los tipos de personajes, o sobre las reglas propias de géneros narrativos. Los cuentos son la clave para iniciar a los niños en la literatura y en la cultura que les precede.

Este proyecto didáctico se ha llevado a cabo en las aulas de la Facultad de Educación de la Universidad Complutense durante varios cursos, en las asignaturas de "Literatura y educación" y "Lectura y escritura creativa" de Magisterio. Los objetivos principales del proyecto abarcan los siguientes aspectos:

- Recuperar el hábito lector y la motivación por la escritura a partir del bagaje cultural de los cuentos tradicionales.

- Aumentar la empatía y la conciencia crítica sobre la igualdad de género a través de la escritura creativa y colaborativa en las aulas.

- Crear y leer antologías temáticas de cuentos para la educación emocional y la formación en valores equitativos y tomarlas como modelo para la escritura. 
- Motivar la creatividad a través de la escritura colaborativa con tecnologías digitales multimedia.

- Crear textos digitales con aplicaciones en línea y redes sociales.

Aparte de conocer en profundidad los orígenes y la evolución de los cuentos tradicionales, es importante desde un punto de vista didáctico reflexionar sobre las ventajas de dichos cuentos para la adolescencia (Jover Olmeda, 2015). Por eso se parte de una serie de preguntas iniciales: ¿Son interesantes los cuentos tradicionales en la educación actual a pesar de sus elementos truculentos 2 ? ¿Cómo y con qué propuestas didácticas se pueden rescatar en las aulas de Primaria y Secundaria de una forma creativa?

Antes de revisar las teorías psicológicas, antropológicas y feministas sobre los cuentos, se va a reflexionar sobre algunas de las ventajas de dichos relatos para las aulas:

a. Los relatos captan la atención del auditorio durante más tiempo y permiten por lo tanto profundizar en el conocimiento del lenguaje. Son la base tanto para aprender a leer y a escribir como para empezar a reconocer lo que está bien y lo que está mal.

b. Una de las funciones más importantes de la literatura, y del cuento en particular, es el desarrollo de la empatía hacia los problemas y avatares ajenos, porque ayudan a conocer las formas de pensar y actuar de los demás, abriendo así la mente. Los cuentos son los primeros modelos de sociedad que conocemos antes de salir del hogar y nos enseñan a relacionarnos con los otros, son una fuente de socialización indiscutible.

c. Asimismo los relatos inducen a percibir la diferencia entre su época y el tiempo del relato, desde la misma fórmula de apertura del cuento: "Érase una vez..." o "Había una vez...". Narran la vida de los pueblos pasados, sus antecesores, creando la noción de historia de la humanidad. No sólo son guías psicológicas sino también documentos históricos, ya que, como se verá en el apartado siguiente, los cuentos cambian y se adaptan a las costumbres de cada tiempo y sociedad.

d. Los detalles violentos no afectan verdaderamente, son inocuos por entrar dentro del pacto de ficción que se establece con los lectores; desde la misma fórmula de inicio del cuento el oyente sabe que se entra en un mundo diferente. Por otra parte, los miedos no empiezan con los cuentos, muy al contrario, estos sirven para dejar aflorar las preocupaciones preexistentes, compartirlas y exteriorizarlas. En palabras de Rodari "ese lobo puede asustar a un niño solo en la medida en que él tenga dentro de sí un terror oscuro" $(2017,37)$.

e. Las teorías psicoanalíticas atribuyen siempre a los cuentos un efecto terapéutico sobre el desarrollo de la psique infantil; no solo no aumentan los miedos, sino que ayudan a los niños a verbalizar sus problemas y preocupaciones más

¿A qué edad empiezan a rechazarlos y cuál es la razón? Sobre esta pregunta se reflexiona, a partir de cuestionarios en las aulas, en mi artículo (García Carcedo 2018b), ya que se está llevando a cabo una investigación de hábitos lectores a partir del quinto curso de Primaria. Se puede profundizar asimismo en la metodología necesaria para el análisis de conductas lectoras en Bortolussi $(1985,102)$, quien piensa que a los niños de hoy dejan de interesarles a la edad de siete años. Véase también Cerrillo, Yubero y Larrañaga (2002). 
profundas. Vladimir Propp, en su obra Las raíces históricas del cuento (1946), explicaba ya que el núcleo más antiguo de los relatos maravillosos deriva de los rituales de iniciación frecuentes en las sociedades primitivas. Esos ritos iniciáticos serán especialmente positivos para el desarrollo de los jóvenes, que nunca deberían apartarse de ese estimulante bagaje cultural transmitido por los cuentos. Se creía que el niño resucitaba como un hombre nuevo (esa muerte simbólica era reflejada en muchos cuentos, en los que, como en Caperucita roja, eran comidos por animales fabulosos para luego ser devueltos a la vida). Propp $(1974,29)$ destacó en todas sus obras la importancia antropológica de los cuentos tradicionales y sus ritos que reaparecen en todos los países: "la similitud de los cuentos del mundo entero" (Propp, 1998, 29).

Su función de rito de iniciación para la vida adulta puede ser especialmente interesante en la adolescencia; Mircea Eliade (1994) afirmaba ya que los cuentos maravillosos continúan transmitiendo sus mensajes iniciáticos, operando mutaciones en el lector activo que se identifica con los relatos: "Aquello que se llama 'iniciación' coexiste con la condición humana, que toda existencia está constituida por una serie ininterrumpida de pruebas, de muertes, y de resurrecciones..." (Eliade, 1994, 47).

Antes de presentar los remotos orígenes orales de los relatos seleccionados, vamos a recordar cómo y cuándo llegaron a difundirse por escrito en nuestras sociedades occidentales. Aunque existen casos de fijación en épocas tempranas, en general, el interés por la recogida y análisis de las tradiciones orales se expandió en el siglo XIX, coincidiendo con el Romanticismo y el comienzo de la alfabetización de las. En España, Fernán Caballero inaugura la figura del recolector con la publicación de Cuentos (1877), donde incluye relatos recogidos de la zona rural de Sevilla. Otro de los momentos clave fue el trabajo difusor de la editorial Calleja de Madrid, que contribuyó a dar a conocer con gran éxito de público los cuentos de Perrault, Grimm o Andersen.

En estas páginas se van a rescatar las versiones menos conocidas de los cuentos tradicionales para usarlas como modelos hacia una escritura creativa y digital, porque escribir es una aventura, como afirma Ana Pelegrín (2008):

El escritor, el poeta, parte siempre hacia la aventura, hacia el viaje, atraviesa duras pruebas [...] para transgredir los márgenes impuestos por una realidad dominante, buscando otra realidad para transformarla con su acción-palabra. (Pelegrín, 2008, 18).

\section{Educación en igualdad. Feminismo y polémicas sobre los cuentos}

Érase una vez... y otra vez... Las bellas duermen en sus bosques, esperando que los príncipes lleguen para despertarlas. Bellas, pero pasivas; por tanto deseables. De ellas emana todo misterio. Es a los hombres a quienes les gusta jugar a muñecas. Como es sabido desde Pygmalion (Cixous, 1975, 17).

Nos preocupa especialmente el hecho de que determinadas críticas recientes puedan conducir al rechazo de una fuente cultural tan importante como los cuentos tradicio- 
nales; por eso se van a revisar dichos enfoques para tratar de rescatar una tradición siempre provechosa para los jóvenes.

La crítica feminista, sobre todo a partir de la segunda mitad del siglo XX, trata de anular los estereotipos de la feminidad en nuestra sociedad, a veces tan aceptados que parecen naturales, cuando en realidad están determinados por ideas culturales cerradas sobre la mujer. Tal es el caso de los cuentos tradicionales, con sus princesas bellas y pasivas, que muchos estudios feministas ${ }^{3}$ denuncian como símbolos de la sociedad patriarcal. Desde las primeras críticas de Simone de Beauvoir en El segundo sexo (1949), donde denuncia la pasividad de las heroínas tradicionales presentadas como víctimas que siempre esperan que las salve un hombre y alude a las Cenicientas y Bellas durmientes a las que urge a despertar para que tomen las riendas de su propia vida. Posteriormente, María Tatar (2012), editora de una magnífica antología de los cuentos, calificará estas historias que implican una aculturación para la mujer, crítica que será desarrollada por Marcia Lieberman (1972) y por Sandra M. Gilbert y Susan Gubar (1979).

En el ámbito de la literatura infantil, Adela Turín o a Elena Giannini han sido pioneras en abordar ya a finales del siglo pasado la cuestión de los estereotipos en la literatura para niños. Arturo y Clementina de Adela Turín fue uno de los cuentos más emblemáticos con perspectiva feminista ya en la década de los 70 , en el que la protagonista se liberaba: "Clementina empezaba a ser verdaderamente feliz y las regañinas de Arturo ya no le importaban. Y un día Arturo encontró la casa vacía” (Turín, 1976).

Dentro de la corriente feminista más ortodoxa, Hélène Cixous (1975) considera que los cuentos de hadas atrapan a la mujer desde la infancia en un modelo cultural falogocéntrico que anula su capacidad de acción. Tratan dichos estudios asimismo de desmontar el mito del amor romántico como una obligación del patriarcado que pretende ser un proyecto femenino pero en realidad oprime a las mujeres.

Desde finales del siglo XX, múltiples narradoras y narradores han rescatado a las princesas de esa pasividad convirtiéndolas en seres activos que se salvan a sí mismas en los relatos, como se puede comprobar en el estudio de Rosemary Lake (2001). Hasta el punto de que son Caperucita misma y su abuela las que se ríen dentro de la tripa del lobo y con una tijera la cortan desde dentro para liberarse. O en la Caperucita en versión lésbica de Olga Broumas publicada en $1977^{4}$, donde ni siquiera aparece el lobo feroz. $\mathrm{O}$ en las conocidas versiones políticamente correctas (que se mostrarán más adelante) de Finn Garner (1998).

La revisión de los cuentos se traslada incluso a otros géneros, como el conocido poema de la española Miriam Reyes, en el que se destacan las intenciones lascivas de todos los que desean despertar en la obra Bella Durmiente:

...quiere despertarme

para que pruebe mis méritos sobre su mesa.

Yo no le pedí nunca nada a ninguno.

\footnotetext{
Se puede partir de una clasificación de los estudios feministas más actuales, en la que Linda Alcoff (1989) distingue entre el feminismo cultural y el feminismo posestructuralista. La segunda corriente rechaza cualquier definición de la mujer. Por lo tanto, se sostiene que hay que buscar un nuevo enfoque a la subjetividad femenina y propone una definición posicional de la identidad de la mujer que partiría de la relación de la mujer con sus circunstancias históricas y sociales externas (Alcoff, 1989, 416-433).

4 Cuento de Broumas incluido en la antología de Zipes (1993, 272-273).
} 
Pero todos tienden sus manos

para ensuciar la blancura que les deslumbra (Reyes, 2004, 61).

Entre los defensores de los cuentos desde el psicoanálisis está Bettelheim (1999), quien afirma que el tema del cuento es la incipiente sexualidad de la niña que los padres tratan de evitar, ya que tiene que esperar cien años. Bettelheim destaca que la pasividad, en una cierta fase del desarrollo psíquico de los jóvenes, puede llegar a ser sana porque implica aprender a esperar (Bettelheim, 2010, 304-305).

La crítica feminista, en el extremo contrario, ve en la imagen arquetípica de esa mujer bella y pasiva una imposición social que coarta la libertad de acción femenina. Las pensadoras de la escuela francesa, especialmente la mencionada Cixous, han tratado de desenmascarar la pasividad, como uno de los medios de anulación femenina: "O la mujer es pasiva; o no existe" (Cixous, 1995, 15).

Finalmente, en nuestra opinión, hay efectivamente aspectos del cuento en las versiones escritas que reflejan una sociedad machista: el ansia de matrimonio, la figura del héroe masculino libertador y el ideal de belleza estereotipado. Pero eso no quiere decir en absoluto que se deban rechazar los cuentos tradicionales en la educación de los jóvenes, sino que, por el contrario, es muy necesario recurrir a ellos para que conozcan los defectos de las sociedades y se pueda reflexionar en las aulas sobre dichos comportamientos machistas y sobre cómo modificarlos.

De hecho la crítica feminista demasiado simplificadora comienza a superarse en la actualidad. Stone (1989), por ejemplo, señala que estas posturas en las que los cuentos de hadas se atacan como generadores de problemas en lugar de fuentes de soluciones a los conflictos, tal como los interpretaba el psicoanálisis, han dado lugar a una visión cerrada y roma de los roles de género que se convertiría asimismo en estereotipo:

Feminist writings [...] have been concerned with the effects of gender stereotyping and have justifiably aimed their criticisms at popularly known tales. In so doing they tend to attack the same heroines -notably Cinderella, Snow White, and Sleeping Beauty- again and again, until the feminist view of such heroines has itself become a stereotype (Stone, 1989, 230).

La crítica simplista hacia los cuentos empieza de hecho a desaparecer para hacerse más abierta y seguir apreciando también las aportaciones beneficiosas de los cuentos y la ignorada fortaleza de las protagonistas femeninas. Madonna Kolbenschlag destaca en Adiós, Bella Durmiente (1994) tanto lo positivo como lo negativo de las féminas reflejadas en los cuentos, y advierte de que solo si hombres y mujeres comprenden la complejidad y la oposición de sus fuerzas podrán abrirse a la transformación. Otros proponen la reescritura femenina como la propia Valenzuela $(2001)^{6}$, en su ensayo "Escribir el goce", que reivindica la superación del pensamiento lacaniano, que quedaba posicionada fuera del lenguaje y por tanto ajena al conocimiento:

"Los estudios feministas se han visto afectados por la estéreo-tipificación de género y han enfocado su crítica hacia los tan conocidos cuentos populares. Y al hacerlo han atacado a sus mismas heroínas -Cenicienta, Blancanieves, Bella Durmiente...- una vez y otra vez, hasta que la visión feminista de dichas heroínas se ha convertido ella misma en un estereotipo" (La traducción es mía).

6 La obra de Valenzuela se estudia en profundidad en Markovic, A.(2009). 
Hoy, más de 35 años después [...] gran cantidad de mujeres han logrado tomar al lenguaje por las orejas para sacarlo de la senda trillada y marcarle nuevas huellas (de la lucha contra la invisibilización marcada por el lenguaje), y son muchas, para bien o para mal las mujeres que le dan un uso pernicioso: ¡escriben! (Valenzuela, 2001, 42).

Por otra parte, se puede más bien culpar del machismo a los recopiladores -Perrault, los hermanos Grimm o las primeras películas Disney sobre todo- de censurar aspectos presentes en la tradición oral como el sexo y la iniciativa femenina. Los distintos finales antiguos, por ejemplo de las Caperucitas Rojas orales previas ${ }^{7}$ a las versiones de Perrault, no presentaban una niña pasiva, sino una heroína activa que se escapaba del lobo con un truco por su propia iniciativa, sin que nadie la rescatara. La tradición oral de la mayoría de los cuentos no estaba tan marcada por el machismo como las versiones escritas posteriores. Por eso se presentan a continuación las versiones orales antiguas de los dos cuentos seleccionados, que se remontan nada menos que hasta el año 1500 antes de Cristo en Egipto.

\section{Experiencia de escritura creativa y digital en las aulas}

La literatura infantil es el mejor lugar en el que encontrar el mundo que soñamos. (Regueiro, 2015).

Este proyecto didáctico se ha desarrollado en las aulas de la Facultad de Educación de la Universidad Complutense durante varios cursos, en las asignaturas de "Literatura y educación" y "Lectura y escritura creativa" de Magisterio Primaria y en el Máster de Secundaria. La metodología se ha basado en el Aprendizaje Basado en Proyectos (ABP o PBL, Project-Based Learning), una estrategia de enseñanza centrada en la valoración del alumnado como protagonista de su propio aprendizaje. Se han extendido las experiencias de escritura creativa más allá del papel realizando asimismo ejercicios multimedia en pantallas (recopilados en la web que se describe unas líneas más abajo). La motivación que conlleva el uso de tecnologías digitales en las aulas ha sido suficientemente demostrada por numerosos especialistas, entre los que destacan Mendoza Fillola (2012), Lluch (2007), Grupo LEETHI (García Carcedo, coord., y Grupo LEETHi, 2008) o Cerrillo (2016), llegando todos a la conclusión de que el lector nuevo es el consumidor fascinado por las nuevas tecnologías, el adolescente que solo lee en la red.

El proyecto ha incluido el estudio de la escritura digital, ya que la relación entre texto, autor y lector se ha transformado totalmente en la red, como se puede comprobar en la obra del Grupo LEETHi Alicia a través de las pantallas. Lecturas literarias del siglo XXI (García Carcedo y Goicoechea, 2013). Por todo ello en esta experiencia los alumnos han realizado versiones de los cuentos en digital (videos, blogs, Facebook, Whatsapp, etc.) que se pueden consultar en la web $2.0 \operatorname{Tropos}^{8}$ que

Para conocer esas versiones orales antiguas se puede consultar García Carcedo (2018a), así como mi libro Educación literaria y escritura creativa (García Carcedo 2011).

8 Se trata de una página colaborativa, en la que no solo se encontraréis ejemplos de nuestros alumnos que sirven como modelo para la escritura 2.0 en las aulas literarias, sino que también podéis enviar ejercicios y fichas de 
hemos creado en el grupo LEETHI: http://repositorios.fdi.ucm.es/Tropos. Es una Biblioteca de Escritura Creativa Digital que pretende sistematizar una metodología para el aprendizaje de la literatura a partir de la escritura en Internet. Cada uno de los ejemplos de escritura de Tropos viene acompañado de una ficha didáctica donde se ofrecen unas pautas para facilitar su reusabilidad, de manera que resulten útiles para cualquier profesor de Primaria, Secundaria o Universidad que encontrará aquí ideas y propuestas para enriquecer su práctica docente.

Se seleccionan asimismo a continuación algunas versiones digitales realizadas por los alumnos sobre cuentos tradicionales menos conocidos:

- "La hilandera holgazana" de Grimm es un curioso montaje de dibujos realizados por los propios estudiantes ${ }^{9}$ en video en la siguiente dirección https:// www.youtube.com/watch? $\mathrm{v}=\mathrm{nWfMh}-\mathrm{ZR} 0 \mathrm{PU}$. En esta versión, también pensada para la liberación femenina, la mujer es la protagonista inteligente que consigue salirse con la suya y engañar al controlador marido.

- "La muerte madrina" es una versión digitalizada ${ }^{10}$ con herramientas como Genial.ly y Powtoon, con el resultado de un mapa interactivo en el que el internauta tiene que elegir los iconos de la pantalla y en cada uno verá un video diferente (como en la ilustración). Se puede visualizar en https://view.genial. ly/5a394c064b36570c14189218/la-muerte-madrina.

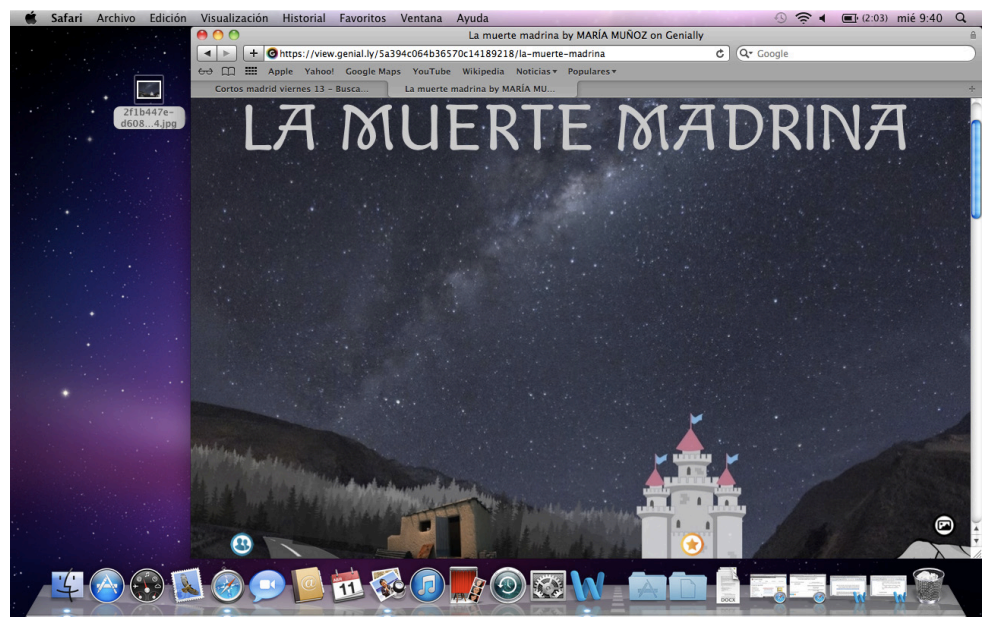

Figura 1. Captura de pantalla del mapa interactivo de alumnos UCM.

calidad de vuestras propias experiencias y las incluiremos en Tropos. Disponible en: http://repositorios.fdi.ucm. es/Tropos, web coordinada por Begoña Regueiro de la Universidad Complutense de Madrid.

9 Autores de la versión del cuento los estudiantes del Máster de Secundaria: Música: Rodrigo Martínez, ,Folia‘ (1490), interpretada por Jordi Savall. Adaptación: Milagros Reixach. Voz y sonido: Clara Luna García. Documentación: Magdalena del Rocío Contreras y Luis Luciano Ramírez. Animación: Jacinto Martínez.

10 El grupo del Máster compuesto por Isabel Bermejo, Pablo Segura, Nerea Díaz, María Muñoz y Eva Torrejón ha realizado una digitalización del cuento de los hermanos Grimm titulado "La Muerte Madrina". 


\section{Las primeras Cenicientas}

La muchacha se cortó el dedo, metió a la fuerza el pie en la zapatilla y, ocultando su dolor, se presentó ante el hijo del rey (Grimm, 2001, 61).

Los cuentos tradicionales se ubican a partir de la clasificación del folclorista Aarne-Thompson (1961) (en adelante AT) ${ }^{11}$; en este caso, la Cenicienta es el cuento del subtipo 510A y tiene una larga historia que se va a tratar de resumir a continuación. Se encuentran las primeras fuentes escritas, como se ha dicho, en el Antiguo Egipto con la historia de Ródope (Rhodopis: "mejillas rosadas"

En el cuento, Ródope es raptada por piratas, que la venden como esclava en Egipto. Las otras esclavas no tardan en sentir celos, burlarse de ella y cargarla con las tareas más humillantes, como en Cenicienta. Mientras se bañaba en las aguas del Nilo un halcón (el dios Horus encarnado) le robó una sandalia y la dejó caer sobre el faraón, que viajó a lo largo del Nilo en busca de la doncella de la sandalia que tanto le obsesionaba. Así, llegó al palacio donde vivía Ródope y quedó claro que era la dueña. El faraón, que se había enamorado, le pidió que se casase con él y así fue como se convirtió en reina de Egipto. Existen otras versiones, realizadas por Heródoto y Estrabón ${ }^{13}$, con variantes sobre la historia de Ródope, en la que la presentan como una famosa cortesana de la que se enamoró el faraón.

Cenicienta es desde luego uno de los cuentos más conocidos, sus orígenes no solo los encontramos en Egipto, sino que tiene asimismo versiones escritas ya registradas en el siglo IX d. C. en China (Bettelheim, 1999, 245). Este origen oriental es relevante, puesto que nos explica la trascendencia de uno de los elementos más significativos del cuento de Cenicienta, las zapatillas de oro o cristal que sólo encajan en un pie diminuto, detalle que implica connotaciones de belleza y sensualidad en el mundo oriental, donde tenían la terrible costumbre de vendar los pies a las mujeres para que no crecieran.

Se pueden encontrar asimismo cuentos con muchas similitudes en la tradición rusa, por ejemplo El Rey del frío recopilado por Afanasiev (2008) ${ }^{14}$, donde la protagonista se llama Marfutka, pero vive también muchas penalidades trabajando para su madrastra y sus desagradables hermanastras, que la insultan continuamente: "Como sucede casi siempre, la madrastra no dejaba nunca en paz a la pobre muchacha y la regañaba constantemente por cualquier pretexto. -iQué perezosa y sucia eres!..." (puede consultarse el cuento en: ciudadseva.com/texto/el-rey-del-frio/).

En la versión escrita de Jacob y Wilhelm Grimm en el siglo XIX, aunque se ha suavizado ya el cuento adaptándolo a la infancia, se ofrecen todavía una serie de detalles algo truculentos sobre el tamaño del pie de las hermanastras:

11 El sistema Aarne-Thompson-Uther, o AT, es para la clasificación de fábulas o cuentos de hadas; su primera edición fue obra del folclorista finlandés Antti Aarne, publicado en 1910. En el sistema de clasificación de Aarne-Thompson, la Cenicienta se adscribe al grupo de los cuentos folclóricos ordinarios, dentro de él, al de los ayudantes sobrenaturales (500-559), y en concreto al subtipo 510A, el de la heroína perseguida.

12 La vida de la Ródope histórica apenas permanece en algunas referencias en las obras de Safo (620 a.C-580 a.C) y del geógrafo Estrabón (64 a.C-24 d.C), sin embargo sí ha permanecido íntegra hasta nuestros días la leyenda de la que es protagonista y que la sitúa como reina de Egipto.

13 Herodoto: Los nueve libros de la historia. Libro II. Disponible en: https://es.wikisource.org/wiki/Los_nueve_libros_de_la_Historia:_Libro_II (consultado el 3 de septiembre de 2017).

14 Versión en verso del "Rey del frío" adaptada por una alumna de la Universidad Complutense, fragmento: "Con un frío anciano / la quiso casar la malvada, / pero volvió con riqueza en mano / despertando envidias guardadas. / Las hermanas probaron suerte / pero acabaron recibiendo la muerte [...]" (Adaptación de Lara de Diego). 
Entonces su madre le tendió un cuchillo y le dijo:

-Córtate el dedo; cuando seas reina no necesitarás ir a pie. (Grimm, 2001, 61).

Con el paso del tiempo y con la fijación de los cuentos tradicionales en la escritura este tipo de detalles violentos se fueron censurando, buscando elementos menos inconvenientes para el nuevo público infantil (García Carcedo, 2004). Hasta llegar a las versiones de Disney por todos conocidas o a películas ${ }^{15}$ y cortometrajes menos difundidos como el de Betty Boop en inglés que se pueden encontrar en Internet: https://archive.org/details/Betty_Boop_Poor_Cinderella_1934\#.

Hasta llegar a las famosas versiones politicamente correctas de Finn Garner (1998), donde las cenicientas se liberan de la moda y de sus obligaciones patriarcales:

Liberada del estorbo de su túnica y de sus zapatos [...] Las mujeres que la rodeaban [...] comenzaron a desprenderse de los corpiños, corsés, zapatos y demás prendas que las limitaban. Inmediatamente, empezaron a bailar, a saltar y a gritar de alegría, pues se sentían al fin cómodas con sus prendas interiores y sus pies descalzos (Garner, 1998, s. p.).

\subsection{Propuestas didáctica: Microrrelatos}

Todas las propuestas didácticas que se hacen en estas páginas están pensadas para desarrollar una conciencia de igualdad de género en quinto y sexto curso de Primaria y en Secundaria, pudiendo ser adaptadas por los profesores a cada uno de esos cursos. En este caso, tras leer las diferentes versiones de la Cenicienta, se va a dejar volar la imaginación escribiendo un microrrelato que invierta los estereotipos del cuento (por ejemplo desde la perspectiva de las hermanastras). Una de las envidiosas hermanas de Cenicienta podría ser la nueva narradora del relato breve (en primera o en tercera persona). Se va a permitir que las hermanastras expongan su perspectiva ya que recibieron un castigo tan terrible en la versión de Grimm del cuento:

Al llegar el día de la boda, se presentaron las traidoras hermanas [...] las palomas, de sendos picotazos, les sacaron un ojo a cada una. Y de este modo quedaron castigadas por su maldad, condenadas a la ceguera para todos los días de su vida (Grimm 2007, s. p.).

Antes de empezar a escribir microrrelatos, hay que recordar las claves de este género tan contemporáneo (véase García Carcedo y Regueiro, 2015). El microrrelato no sólo debe ser breve sino también muy intenso, de forma que requiere una gran labor de interpretación por parte de lectores muy activos. Los microrrelatos son como los icebergs, solo una pequeña parte de la historia asoma a la superficie, pero tiene que ser tan sugerente que lleve al lector a descubrir todo el resto de la historia

15 Son interesantes las versiones cinematográficas de la Cenicienta con personas reales, por ejemplo, las de 1985 o la más actual norteamericana de 2015, dirigida por Kenneth Branagh. Existen asimismo múltiples versiones teatrales e incluso óperas, como la de Rossini estrenada ya en 1817 que se tituló en italiano: La Cenerentola, ossia la bontá in triunfo. En esta versión musical la malvada madrastra es sustituida por un padrastro, Don Magnifico, y el Hada madrina es reemplazada por Alidoro, un filósofo y tutor. 
oculto en las profundidades marinas. Para escribir un microrrelato hay que llegar al punto clave o clímax de la narración, en el que se producirá un giro inesperado que sorprenda al lector. Se leerán en el aula algunos ejemplos de microrrelatos famosos para tomarlos como modelo, como estos dos ejemplos seleccionados:

Calidad y cantidad [de Alejandro Jodorowsky]

No se enamoró de ella, sino de su sombra. La iba a visitar al alba, cuando su amada era más larga (Jodorowsky 2003, 43)

Fantasma [de Patricia Esteban Erlés]

El hombre que amé se ha convertido en fantasma. Me gusta ponerle mucho suavizante, plancharlo al vapor y usarlo como sábana bajera las noches que tengo una cita prometedora (Esteban Erlés, 2012, 117)

También son muchos los autores que han escrito microrrelatos basados en cuentos tradicionales, como René Avilés Fabila, en su obra compilatoria Fantasías en carrusel (1995). Incluso algunos microrrelatos de este tipo se han hecho famosos en Twitter, como los de José Luis Zárate:

A las 12 desapareció la magia. El carruaje se transformó en calabaza, el vestido en harapos, el Príncipe Azul en el cretino que solía ser (2012a).

Fue fácil encontrar a Cenicienta, solo se siguió el rastro de sangre que deja cualquiera que huye con zapatillas de cristal. (2012b).

A continuación, en la presente propuesta didáctica, cada estudiante de Magisterio escribe su microrrelato basado en la Cenicienta, desde una perspectiva de igualdad de género, buscando la intensidad y la sorpresa:

Y de tanto salir corriendo... Cenicienta empezó a salir descalza (Sergio Belinchón Abad).

Y cuando llegó la calabaza Cenicienta se quedó muerta, nunca había visto nada igual. Le pidió de rodillas al hada que le dejase darse una vuelta y así fue como Cenicienta no volvió jamás (Victoria González Baldomero).

El hada madrina le concedió su mayor deseo, tener su título universitario y viajar por todo el mundo disfrutando de la vida con sus amigas (Erika Castro).

Trueque: Cuando el príncipe le devolvió el zapato de cristal a Cenicienta, ella le dio calabazas (Marta Coronado).

En las aulas de Magisterio de la Universidad Complutense, después de escribir los microrrelatos individuales los estudiantes han realizado versiones digitales de los cuentos en grupo, una selección de las cuales se puede consultar en la mencionada web Tropos: Biblioteca digital de escritura creativa. 


\section{La Bella durmiente se enfrenta al ogro}

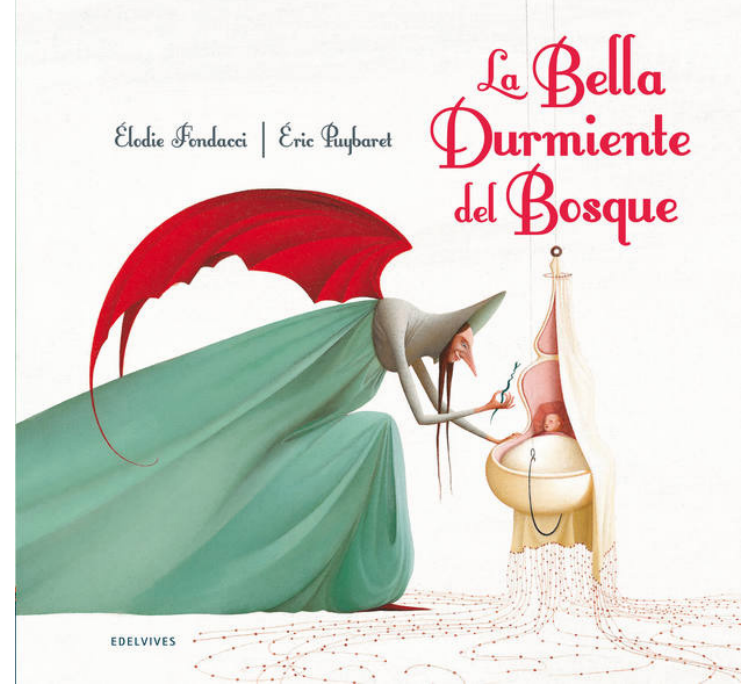

Figura 2. Ilustración de Éric Puybaret.

En las versiones actuales se han omitido las tremendas peripecias posteriores de la hermosa princesa contadas por Perrault, porque el cuento original no terminaba con la boda sino que continuaba con una conflictiva relación con la suegra-ogro. Se conocen lejanos antecedentes indios, greco-latinos, islandeses, etc. en los que el germen del relato de La Bella durmiente ya está presente:

- Saga volsunga (relato islandés anónimo del siglo XIII ${ }^{16}$ ): El dios Odín odia a Brunilda y la encierra dormida en un castillo remoto protegido por escudos. El héroe Sigurd (el Sigfrido del Cantar de los nibelungos) es quien finalmente la encuentra.

- Surya Bai (Frere, 2003): La erudita italiana Ester Zago (1991) sostiene que varias de estas versiones se derivan de una leyenda india. Según este relato la hija de una lechera es secuestrada por un águila que la cría en lo alto de un árbol. Las águilas la llaman Surya Bai ("Dama del Sol”) y un día la dejan en el árbol protegida tras siete puertas. Cuando Surya Bai abre las puertas, se clava la uña de un demonio en la mano y queda inconsciente. Finalmente, un Rajá que está de cacería en el bosque divisa el nido y logra despertar a la hermosa dama del sol.

- Blandín de Cornualles (poema occitano-catalán de principios del siglo XIV): Brianda cae en un sueño profundo y su padre la recluye dormida en un castillo custodiado por diez caballeros, una serpiente, un dragón y un sarraceno. Blandín vence a estos guardianes y despierta a la princesa por medio de un pájaro.

16 Las sagas de los islandeses tratan de la vida, conflictos y peleas de diversas generaciones de vikingos en los siglos X y XIII. La que mencionamos se puede leer en Saga de los volsungos (1998). 
- Otra versión del cuento más reciente fue publicada antes de Perrault en Italia, en 1636 por el mencionado recopilador Basile (2006). En la versión italiana la protagonista se llama Talía y, cuando ya se ha pinchado con una astilla envenenada, la descubre un noble, que, en vez de limitarse a darle un beso, la viola; más tarde, Talía, aún dormida, tiene dos gemelos, llamados Sol y Luna. El niño chupa el dedo de su madre y extrae la astilla envenenada, con lo que Talía se despierta; el cuento original se va complicando cada vez más hasta que los gemelos están a punto de ser cocinados y comidos, pero los salva el cocinero.

Una vez más referencias antropofágicas que reaparecerán todavía, aunque modificadas, en la versión de Perrault. En las Histoires ou Contes du temps passé, la historia de La Bella durmiente no termina felizmente con su encuentro con el príncipe, sino que la esperan todavía un sinfín de peripecias. Tienen dos hijos, un niño y una niña, Aurora y Día, y sucede que la Reina madre, aprovechando que el príncipe se ha ido a la guerra le dice al mayordomo:

-Mañana quiero comerme a la pequeña Aurora en la comida... - dijo la Reina (y lo dijo con el tono de una ogresa que tiene ganas de comer carne fresca)-, y quiero comérmela con salsa Robert (Perrault, 2001, 116-117).

En las interpretaciones psicológicas de este relato volvemos a ver el tema del rito iniciático adolescente, esta vez en su versión femenina, de forma que el pinchazo y la sangre simbolizan la primera hemorragia menstrual y el beso la mencionada iniciación sexual. Por su parte, la crítica feminista ha tomado a la protagonista, condenada a la pasividad en espera de un varón que la salve, como símbolo de la situación de la mujer en la sociedad patriarcal.

Se pueden poner múltiples ejemplos de reescrituras feministas de los cuentos, o referencias intertextuales como el relato de Luisa Valenzuela " "Cuarta versión", donde la protagonista lleva el nombre de Bella, invocando el cuento de hadas que transmite al imaginario social una idea de lo femenino que se identifica con lo bello, frágil y pasivo. También en palabras de la poetisa feminista María Montero se puede observar la crítica de esa pasividad de la mujer que viene siendo simbolizada por $L a$ Bella durmiente:

La que duerme sin tener sueño

o se hace la dormida para estar más sola (Montero, 2006, 19).

Es contraproducente, sin embargo, introducir un significado unívoco o críticas demasiado explícitas en los relatos. Hay que recuperar los cuentos tradicionales tal y como aparecían en dichas sociedades para establecer un debate en las aulas sobre la equidad de género y tratar temas de tanto interés a través de la escritura creativa.

17 "Si la mujer no existe, como una vez dijo Lacan, los relatos de Valenzuela a la vez confirman esta idea, enseñando las formas de la (in)existencia de la mujer en una cultura patriarcal, y buscan la posibilidad de crear un nuevo sentido existencial fuera de las construcciones masculinas. Nuestra hipótesis propone que Valenzuela muestra que tanto los cuentos de hadas, que tipifican una modalidad discursiva "falogocéntrica", como los actos discursivos y simbólicos descritos en sus relatos sobre la dictadura argentina, forman un conjunto de procedimientos a través de los cuales se establece la identidad femenina, se define su sexualidad y se restringe su palabra: en este sentido, los relatos de Valenzuela son piezas de resistencia" (Markoviç, 2009, 70-85). 


\subsection{Propuesta didáctica: La princesa decide (en vídeo)}

En esta ocasión se propone imaginar cómo se despierta la princesa y si la tiene que besar un príncipe o no. Después cada uno continúa la historia como quiera, pero, cuando la protagonista se despierta por fin, se plantea si realmente le apetece o le conviene casarse con el príncipe o si desea hacer otras cosas en la vida. De esta forma se añadirá un enfoque feminista al final de este cuento donde la protagonista ha sido siempre el símbolo de la pasividad femenina.

Se propone además que las nuevas versiones de La Bella durmiente tengan finales abiertos, que son una de las características innovadoras de la literatura infantil más reciente según un estudio estadístico de Teresa Colomer ${ }^{18}$ :

[...] el uso de los finales abiertos revela así que los libros infantiles y juveniles han cambiado, no solo porque traten nuevos temas con nuevos propósitos morales sino también porque desean propiciar aprendizajes más sutiles y directamente artísticos, como el aprendizaje de la ambigüedad (Colomer 2005, 212).

Tras haber realizado en grupos el ejercicio de escritura en papel (para lo que pueden inspirarse en Dahl, 2015), tendrán que crear un video de forma libre, utilizando las aplicaciones o formatos que deseen para sacar el máximo partido literario a las posibilidades multimedia (Moviemaker, Stopmotion, VideoScribe, Face Swap... con dramatizaciones, mimo, títeres, sonido y música, etc.). Se incluyen solo dos ejemplos de los estudiantes de Magisterio:

Ella por fin despertó. Entonces abrió los ojos y vio a su soñada princesa azul (José Antonio Aguado Corral).

-¡Cinco minutitos más por favor! -rogó la Bella Durmiente- (Marta Chillón).

En todo caso es importante añadir que las valoraciones de los estudiantes de Magisterio que han llevado a cabo este proyecto didáctico han sido muy positivas $\mathrm{y}$ todos han coincidido en que la lectura y reescritura de cuentos tradicionales es un recurso muy útil para trabajar en las aulas la equidad de género.

\section{Conclusiones}

La revisión de las versiones adultas antiguas de los cuentos es una estrategia didáctica para que el joven no rechace una tradición tan longeva como enriquecedora. En estas páginas se ha buscado un acercamiento a los cuentos tradicionales desde una perspectiva de lectores activos, porque la mejor manera de sentir complicidad con los textos es practicando la escritura creativa. Las propuestas didácticas han tratado de ser lúdicas y variadas, acercándose al mayor número posible de géneros textuales (y digitales): microrrelatos, poesía, video, etc. Pero siempre desde una perspectiva

18 Colomer (2005) concluye que el 17,42\% de los cuentos actuales estudiados tienen un final abierto. Los datos provienen del análisis de los distintos elementos constructivos de doscientas narraciones infantiles y juveniles publicadas en España entre 1977 y 1990. 
de concienciación hacia la equidad genérica, como se ha podido comprobar en los resultados de las versiones de los relatos escritas en las aulas de Magisterio y en sus adaptaciones digitales en vídeo, con mapas interactivos, etc.

Finalmente, los mencionados resultados para las pantallas de la investigación han profundizado en las posibilidades multimediales de la escritura digital y en completar, con una selección de las producciones de los alumnos, la mencionada web 2.0 del grupo de investigación LEETHi: Tropos una Biblioteca de Escritura Creativa Digital (repositorios.fdi.ucm.es/Tropos).

El análisis de las diferentes versiones de los cuentos tradicionales ofrece en definitiva mucha información sociocultural, por lo que es muy necesario retomar estas tradiciones para comprender la evolución de nuestras sociedades y crear una conciencia crítica de las desigualdades de género y de cómo mejorar la igualdad en la actualidad. Es escuchando y reescribiendo esos cuentos, en todos los niveles educativos, como se forman las bases de los lectores y actores de nuestro futuro.

\section{Referencias bibliográficas}

Aarne, A. (1961): The Types of the Folktale: A Classification and Bibliography, Helsinki, The Finnish Academy of Science and Letters.

Afanasiev, A. N. (2008): Cuentos populares rusos, Madrid, Anaya, 3 vols.

Alcoff, L. (1989): "Cultural Feminism versus Post-Structuralism: The Identity Crisis in Feminist", Signs, 13.3, 405-436.

Avilés Fabila, R. (1995): Fantasías en carrusel (1969-1994), México D. F., Fondo de Cultura Económica.

Basile, G. (2006): El Pentamerón. El cuento de los cuentos, Madrid, Siruela.

Bettelheim, B. (1999): Psicoanálisis de los cuentos de hadas, Barcelona, Crítica.

Bortolussi, M. (1985): Análisis teórico del cuento infantil, Madrid, Alhambra.

Cerrillo, P. (2016): El lector literario, México D. F., Fondo de Cultura Económica.

Cerrillo, P., S. Yubero y E. Larrañaga (2002): Libros, lectores y mediadores, Cuenca, Universidad de Castilla-La Mancha.

Cixous, H. (1975): "Le Rire de la Méduse”, L'Arc, 61, 39-54.

Cixous, H. (1995): La risa de la Medusa: ensayos sobre la escritura, Barcelona, Anthropos.

Colomer, T. (2005): "El desenlace de los cuentos como ejemplo de las funciones de la literatura infantil y juvenil", Revista de educación, $\mathrm{N}^{\circ}$ Extra 1, 203-216.

Colomer, T. (2010): Introducción a la literatura infantil y juvenil actual, Madrid, Síntesis.

Dahl, R. (2015): Cuentos en verso para niños perversos, Madrid, Alfaguara.

Eliade, M. (1994): Imágenes y Símbolos, Carmen Castro (trad.), Barcelona, Planeta-De Agostini.

Esteban Erlés, P. (2012): Casa de muñecas, Madrid, Páginas de Espuma.

Frere, M. (comp.) (2003): "VI. Little Surya Bai”, en Old Deccan Days or Hindoo Fairy Legends Current in Southern India. Collected From Oral Tradition by Mary Frere, edición digital preparada por Philip Brown y J. B. Hare a partir del original de Londres, J. Murray, 1868. http://www.sacred-texts.com/hin/odd/odd10.htm [Consulta: 8 agosto 2018]

García Carcedo, P. (2004): La literatura infantil en el ámbito de lo hispánico: tradición y renovación, Madrid, Liceus. http://www.liceus.com/bonos/compra1.asp?idproducto=198 \&la-literatura-infantil-en-el-ambito-de-lo-hispanico-tradicion-y-renovacion [Consulta: 8 agosto 2018] 
García Carcedo, P. (2011): Educación literaria y escritura creativa, Granada, Grupo Editorial Universitario.

García Carcedo, P. (2018a): "Desde los cuentos tradicionales hacia la escritura creativa 2.0. Propuesta didáctica”, Lenguaje y textos, 47, 37-48.

García Carcedo, P. (2018b): “Otros cuentos tradicionales. Propuesta didáctica para las aulas de Secundaria", Letra 15. http://www.letra15.es/L15-08/L15-08-12-Pilar.Garcia.Carcedo-Otros.cuentos.tradicionales.y.sus.origenes.html [Consulta: 8 agosto 2018]

García Carcedo, P., y M. Goicoechea (eds.) (2013): Alicia a través de las pantallas. Lecturas literarias del siglo XXI, Salamanca, Fundación Germán Sánchez Ruipérez.

García Carcedo, P. (coord.), y Grupo LEETHi (2008): Enseñanza virtual y presencial de las literaturas, Granada, Grupo Editorial Universitario.

García Carcedo, P., y B. Regueiro (eds.) (2015): El reto de escribir. Entre papeles y pantallas, Granada, Grupo Editorial Universitario.

Garner, F. (1998): Cuentos infantiles políticamente correctos, edición digital a partir de la de Barcelona, Circe. https://latorredebabel.wordpress.com/2010/07/25/la-cenicienta-versin-polticamente-correcta-por-james-finn-garner/ [Consulta: 13 abril 2018]

Gilbert, S. M., y S. Gubar (1979): The Madwoman in the Attic: the Woman Writer and the Nineteenth-Century Literary Imagination, New Haven, Yale University Press.

Greenhill, Pauline et al. (eds.), (2018): The Routledge Companion to Media and Fairy-Tale Cultures, Oxford / Nueva York, Routledge,

Grimm, J. y W. (2001): Cuentos, Madrid, Alianza.

Girmm, J. y W. ([2007]): “La Cenicienta”, en Cuentos de Grimm. https://www.grimmstories. com/es/grimm_cuentos/la_cenicienta [Consulta: 8 agosto 2018]

Jodorowsky, A. (2003): El tesoro de la sombra: cuentos y fábulas, Madrid, Siruela.

Jover Olmeda, G. (2015): "La Formación del Profesorado de Educación Secundaria. Revisión y propuestas de futuro", Revista española de pedagogía, 73.261, 219-223.

Kolbenschlag, M. (1994): Adiós, Bella Durmiente, Barcelona, Kairós

Lake, L. (2001): Once upon a time when the Princess rescued de Prince, California, Dragon Tree Press.

Levorato, A. (2003): Language and Gender in the Fairy Tale Tradition, New York, Palgrave Macmillan.

Lieberman, M. (1972): “'Some Day my Prince Will Come': Female Acculturation Through the Fairy Tale", College English, 34.3, 383-395.

Lluch, G. (2007): «Literatura Juvenil y otras narrativas periféricas», en P. Cerrillo et al. (dir.), Literatura Infantil, nuevas lectura y nuevos lectores, Cuenca, Universidad de Castilla-La Mancha, 193-211.

Markovic, A. (2009): La identidad femenina y las relaciones de poder en los relatos de Luisa Valenzuela, tesis doctoral, Barcelona, Universidad de Barcelona. http://www.tdx.cat/ bitstream/handle/10803/116768/MARKOVIC_TESIS.pdf [Consulta:

Mendoza Fillola, A. (2012): Leer hipertextos. Dêl marco Hipertextual a la formación del lector literario, Barcelona, Octaedro.

Montero, M. (2006): La mano suicida, San José, Ediciones Perro Azul.

Navascués, J. de (2012): Wikipedia (y otros monstruos), Sevilla, Los Papeles del Sitio.

Pelegrín, A. (2008): La aventura de oir: cuentos y memorias de tradición oral, edición digital (reed. de Madrid, Cincel, 1984), Alicante, Biblioteca Virtual Miguel de Cervantes.

Perrault, C. (2001): Cuentos completos, Madrid, Alianza.

Propp, V. (1974): Las raíces históricas del cuento, Madrid, Fundamentos.

Propp, V. (1998): Morfología del cuento, Madrid, Akal. 
Regueiro, B. (2015): “Imágenes de mujer moderna en la literatura infantil escrita por mujeres (1900-1939): Sofía Casanova, Carmen Conde y Magda Donato", en La narrativa española (1916-1931), París, Indigo Cote Femmes, 111-129.

Rodari, G. (2017): La escuela de la fantasía, Madrid, Blackiebooks.

Saga de los volsungos (1998): Javier E. Díaz Vera (trad.), Madrid, Gredos.

Stone, K. (1989): "Feminist Approaches to the Interpretation of Fairy Tales", en Fairy Tales and Society: Illusion, Allusion and Paradigm, Ruth Bottingheimer (ed.), Philadelphia, University of Pennsylvania Press.

Tatar, M. (ed.) (2012): Los cuentos de hadas clásicos anotados, Barcelona, Crítica.

Turín, A. (1976): Arturo y Clementina, Barcelona, Lumen.

Valenzuela, L. (2001): Peligrosas palabras, Buenos Aires, Temas Grupo Editorial.

Zago, E. (1991): “Frayre de Joy e Sor de Plaser re-examined", Merveilles \& Contes, 5.1, 68-73.

Zapico Lamela, E. (2015): “CColorín, colorado?”: Las reescrituras contemporáneas de los cuentos tradicionales en la literatura hispánica, tesis doctoral, Salamanca, Universidad de Salamanca.

Zárate, J. L. (2012a): “A las 12 desapareció la magia”, 9 de junio de 2012 [Twitter]. https:// twitter.com/joseluiszarate/status/211489711724830720 [Consulta: 8 agosto 2018]

Zárate, J. L. (2012b): "Fue fácil encontrar a Cenicienta", 9 de junio [Twitter]. https://twitter. com/joseluiszarate/status/211489611057344513 [Consulta: 8 agosto 2018]

Zipes, J. (1993): The Trials and Tribulations of Little Red Riding Hood, Nueva York, Routledge. 